\title{
Addition of Local Hepatic Therapy to Sorafenib in Patients with Advanced Hepatocellular Carcinoma (Stage BCLC C)
}

\author{
Laura Schmidt $^{\mathrm{a}}$ Mark op den Winkel $^{\mathrm{a}}$ Katharina Fischer ${ }^{\mathrm{a}}$ Gundula Straub $^{\mathrm{a}}$ \\ Barbara Rauch $^{\mathrm{a}}$ Philpp Marius Paprottka ${ }^{\mathrm{b}}$ Burkhard Göke $^{\mathrm{a}}$ Frank Thomas Kolligs ${ }^{\mathrm{a}}$ \\ ${ }^{a}$ Department of Internal Medicine II and b Department of Clinical Radiology, University Hospital Munich, \\ Campus Großhadern, Munich, Germany
}

\section{Key Words}

Hepatocellular carcinoma · Chemoembolization .

Sorafenib $\cdot$ BCLC

\begin{abstract}
Background/Aims: For most patients with hepatocellular carcinoma (HCC), diagnosis is invariably done only in the advanced stages of the disease. For advanced, non-metastatic stage, standard therapy is transarterial chemoembolization (TACE). For metastatic disease, the recommended therapy is systemic treatment with sorafenib. In this study, we evaluated the benefit of an additional local hepatic treatment for patients with advanced metastatic disease. Methods: In a retrospective study, we assessed the overall survival (OS), time to progression (TTP), and disease control rate (DCR) in 37 patients with metastasized HCC treated with sorafenib. Sixteen patients received additional local therapy, while 21 patients received only sorafenib. Results: Median OS of patients with combined therapy was significantly higher with 25 months ( $95 \% \mathrm{Cl}$ : 13.7-36.3 months) as compared to 11 months (95\% Cl: 6.2-15.8 months) in patients treated with sorafenib alone. TTP was 7 months $(95 \% \mathrm{Cl}: 5.3-8.7$ months) compared to 5 months ( $95 \% \mathrm{Cl}$ : 3-7 months) and DCR was 87 versus $72 \%$ after 3 months and 31 versus $22 \%$ after 9 months. Conclusion: These data suggest that control of the liver tumor burden by local therapy in combination
\end{abstract}

\section{KARGER}

(c) 2014 S. Karger AG, Base

$0012-2823 / 14 / 0904-0219 \$ 39.50 / 0$

E-Mail karger@karger.com

www.karger.com/dig with sorafenib might prove beneficial for metastasized HCC. Randomised studies are needed to confirm this exploratory finding.

(c) 2014 S. Karger AG, Basel

\section{Introduction}

Hepatocellular carcinoma (HCC) is the sixth most prevalent malignancy and the third most frequent cause of cancer-related death worldwide [1].

In recent years, surveillance programs have led to a higher rate of detection of HCC in earlier disease stages $[1,2]$. However, in most cases HCC is still diagnosed in advanced stages. According to the AASLD (American Association for the Study of Liver Diseases) and the EASL (European Association for the study of the liver) practice guidelines, transarterial chemoembolization (TACE) is the recommended treatment strategy for patients with multinodular disease limited to the liver. For patients with extrahepatic spread of HCC, systemic treatment with sorafenib is recommended [1-3]. Some studies have assessed the efficacy of a combined treatment with TACE and sorafenib in advanced tumour stage compared to

\section{Schmidt and M. op den Winkel contributed equally to this work.}


TACE alone [4-6]. However, these studies recruited patients usually amenable only to TACE $[4,5]$.

Prognosis is poor at the metastatic stage. However, in most cases, the cause of death is intrahepatic progression and liver failure [7]. Patients in the metastatic stage treated with sorafenib might therefore benefit from an additional local hepatic treatment. In this retrospective study, we assessed the outcome of patients with metastasized HCC treated with sorafenib plus TACE compared to patients treated only with sorafenib.

\section{Methods}

\section{Patients}

In the time between 2006 and 2012, 37 patients with HCC at advanced metastatic stage treated at our hospital according to our institutional and interdisciplinary treatment protocol were enrolled. All patients had HCC diagnosed either histologically (19 patients) or by radiologic criteria (18 patients) according to AASLD guidelines [2]. Their medical charts were retrospectively reviewed. We selected 16 patients who were treated with local hepatic treatment (11 patients treated with TACE, 3 treated with radioembolization and 2 patients treated with TACE and radioembolization) and sorafenib simultaneously. We matched a control group of 21 patients who were treated with sorafenib alone. $\mathrm{Pa}$ tients were matched by gender ( $81 \%$ male and $19 \%$ female patients in each group), age (median age was 61 in the combined group and 65 in the sorafenib group), presence of liver cirrhosis (10 patients in the combined vs. 14 patients in the sorafenib group), Child Pugh status ( 7 vs. 10 patients with Child Pugh A, 3 vs. 4 patients with Child Pugh B in the combined vs. the sorafenib group only), primary liver tumour volume (median of 11.5 vs. $12 \%$ in the combined vs. the sorafenib group), location of metastasis (8 patients had lung metastasis in the combined group and 7 patients in the sorafenib only group) and exposed to prior therapies such as resection, radiofrequency ablation, TACE ( $50 \%$ of patients in the combined and $57 \%$ patients in the sorafenib group had a history of HCC therapy prior to the current one).

\section{Treatment}

TACE and Selective Internal Radiotherapy (SIRT)

TACE was performed by the department of interventional radiology by injection of an emulsion of epirubicin and lipiodol into tumour-feeding vessels. Patients underwent the procedure every 8-12 weeks depending on the presence of tumour activity in the follow up CT or MRI result (median of numbers of TACE was 4 (min. 1, max. 10)). SIRT was performed by application of $90-\mathrm{Yt}-$ trium spheres into the tumour environment. Patients who were treated by this therapy received SIRT once or twice.

\section{Sorafenib}

Patients treated with sorafenib were prescribed the standard dose of two tablets of $200 \mathrm{mg}$ twice daily. Recommended dose reduction was done when an adverse event according to CTCAE 3.0 (Common Terminology Criteria for Adverse Events) occurred. Treatment was in general paused 3 days prior and 3 days after
TACE. Treatment for patients treated with sorafenib alone continued until radiologic and symptomatic disease progression or intolerable adverse events occurred.

Follow-Up

All patients treated at our centre were followed up according to our institutional protocol. Follow-up was performed by taking medical history, doing physical examination, blood tests and abdominal MRI or CT plus thoracic CT scan every 8-12 weeks. At each staging Child Pugh score was assessed as long as data was available (for the calculation laboratory values up to 5 days before or after the MRI or CT scan were used when data from the same day was missing). Depending on these results therapy was continued, modified or stopped. For this study, evaluation of therapy response was done retrospectively by analysing the CT scan or MRI according to RECIST (Response Evaluation Criteria In Solid Tumors) 1.0 criteria. [8] Compared to the newer RECIST $1.1 \mathrm{cri}-$ teria, RECIST 1.0 seemed to be more applicable and precise for this study as it allows the measurement of more target lesions [9]. At the end of our evaluation (median follow-up of 8 months), 6 patients were still in treatment in the combination group and 2 patients in the sorafenib group.

\section{Statistical Analysis}

The primary objective was the overall survival (OS), which was defined as the time between the first treatment with TACE and/or sorafenib of diagnosed metastatic HCC and death. The time to progression (TTP) was defined according to RECIST 1.0 [8]. The disease control rate was defined as therapy response including complete remission plus partial response plus stable disease. OS and TTP were estimated by Kaplan-Meier plots and compared by the log-rank test. Baseline patient characteristics were compared by using the Students $t$ test or $\chi^{2}$ test. Significance was set at $\mathrm{p}<$ 0.05 . Statistical analysis was performed using SPSS software version 20 (SPSS, Chicago, Ill., USA).

\section{Results}

\section{Basic Characteristics of Patients and Disease}

The basic demographic and disease characteristics at the beginning of treatment including age, gender, presence of cirrhosis, Child Pugh Score, presence of portal vein thrombosis, location of metastasis, volume of primary liver lesions, prior treatment are listed in table 1. The two treatment groups could be properly compared, as there was no significant difference in any of the characteristics between the two groups. 10 of $16(62.5 \%)$ versus 14 of 21 (66.7\%) patients in the combined versus the sorafenib group had liver cirrhosis, 7 versus 10 patients had Child Pugh status A and 3 versus 4 patients Child Pugh B (median for albumin was 4.2 vs. $4.1 \mathrm{~g} / \mathrm{dl}$ in the combined vs. sorafenib group, median for bilirubin was $1.05 \mathrm{vs.} 1.10 \mathrm{mg} /$ dl, INR was 1.10 in each group, 14 vs. 17 patients had no ascites and no patient suffered from hepatic encephalopa- 
Table 1. Baseline patient and tumour characteristics at the time of first diagnosis of metastases

\begin{tabular}{|c|c|c|c|}
\hline & Sorafenib + TACE/SIRT & Sorafenib & $\mathrm{p}$ value \\
\hline Patients, $\mathrm{n}$ & 16 & 21 & \\
\hline \multicolumn{4}{|l|}{ Gender, n (\%) } \\
\hline Male & $13(81)$ & $17(81)$ & 0.982 \\
\hline Female & $3(19)$ & $4(19)$ & \\
\hline Age, years, mean $\pm \mathrm{SD}(\min -\max )$ & $61 \pm 9(46-76)$ & $65 \pm 9(40-79)$ & 0.204 \\
\hline Presence of liver cirrhosis, n (\%) & $10(62.5)$ & $14(66.7)$ & 0.943 \\
\hline \multicolumn{4}{|l|}{ Child Pugh score } \\
\hline A & 7 & 10 & 0.705 \\
\hline $\mathrm{B}$ & 3 & 4 & \\
\hline Albumin, g/dl (median) & 4.2 & 4.1 & \\
\hline Bilirubin, mg/dl (median) & 1.1 & 1.1 & \\
\hline INR & 1.1 & 1.1 & \\
\hline Hepatic encephalopathy & 0 & 0 & \\
\hline Ascites & 2 & 4 & \\
\hline None & 14 & 17 & \\
\hline Moderate & 1 & 2 & \\
\hline Severe & 1 & 2 & \\
\hline \multicolumn{4}{|l|}{ Etiology of liver cirrhosis, $\mathrm{n}(\%)$} \\
\hline $\mathrm{HCV}$ & $1(10)$ & $3(21)$ & \\
\hline $\mathrm{HBV}$ & $2(20)$ & $2(14)$ & \\
\hline Chronic alcohol abuse & $3(30)$ & $3(21)$ & \\
\hline Alcohol abuse and HCV & $1(10)$ & - & \\
\hline Hemochromatosis & - & $2(14)$ & \\
\hline Cryptogenic & $3(30)$ & $4(28)$ & \\
\hline Portal vein thrombosis (partial/complete) & $2 / 0$ & $6 / 2$ & 0.181 \\
\hline \multicolumn{4}{|l|}{ Location of metastases, $\mathrm{n}(\%)$} \\
\hline Lung & $8(50)$ & $7(33)$ & 0.663 \\
\hline Non-lung & $8(50)$ & $14(67)$ & \\
\hline \multicolumn{4}{|l|}{ Primary liver tumour volume, $\mathrm{n}(\%)$} \\
\hline Median & 11.5 & 12 & 0.723 \\
\hline$<10 \%$ & $8(50)$ & $9(43)$ & \\
\hline $10-25 \%$ & $4(25)$ & $7(33)$ & \\
\hline$>25 \%$ & $4(25)$ & $5(24)$ & \\
\hline Patients with prior therapy, $\mathrm{n}(\%)$ & $8(50)$ & $12(57)$ & 0.666 \\
\hline $\mathrm{AFP}, \mathrm{ng} / \mathrm{ml}$ (median) & $147.5(3.5-5,573)$ & $221.5(4.9-63,837)$ & 0.140 \\
\hline
\end{tabular}

thy). Etiology of liver cirrhosis in both groups was mainly chronic alcohol abuse and viral hepatitis; in two patients, of the sorafenib group liver cirrhosis was due to hemochromatosis; in seven cases, cirrhosis was cryptogenic. Among those patients without liver cirrhosis, three patients of both groups had steatosis hepatis, one patient in the combined treatment group had chronic HBV, and one patient of the sorafenib group had histologically diagnosed fibrosis for unknown reason. In the other patients either no liver disease could be diagnosed or data was lacking. All patients had a good ECOG performance status (Eastern Cooperative Oncology group) 0 to 1. Median liver tumour burden was $11.5 \%$ in the combination and $12 \%$ in the sorafenib group. Twelve patients in each group had more than 3 liver lesions. Location of metastasis was mainly lung ( 8 of 16 patients in the combination and 7 of 21 patients in the sorafenib group) and lymph nodes (6 of 16 and 15 of 21 patients). The majority of patients in both groups had singular metastasis (12 and 16 patients). The median of the whole size of all metastasis was $2.5 \mathrm{~cm}$ (combination group) and $2.0 \mathrm{~cm}$ (sorafenib group). Partial portal vein thrombosis was observed in $12.5 \%$ of the patients ( 2 patients) in the combined group and in $28.6 \%$ of the sorafenib patients (6 patients), complete portal vein thrombosis was observed in 2 patients of the sorafenib only group. Median AFP level was elevated in both groups (147 and $221 \mathrm{ng} / \mathrm{ml}$ ). Prior therapies comprised in both groups resection, RFA (radiofrequency ablation) or TACE. 


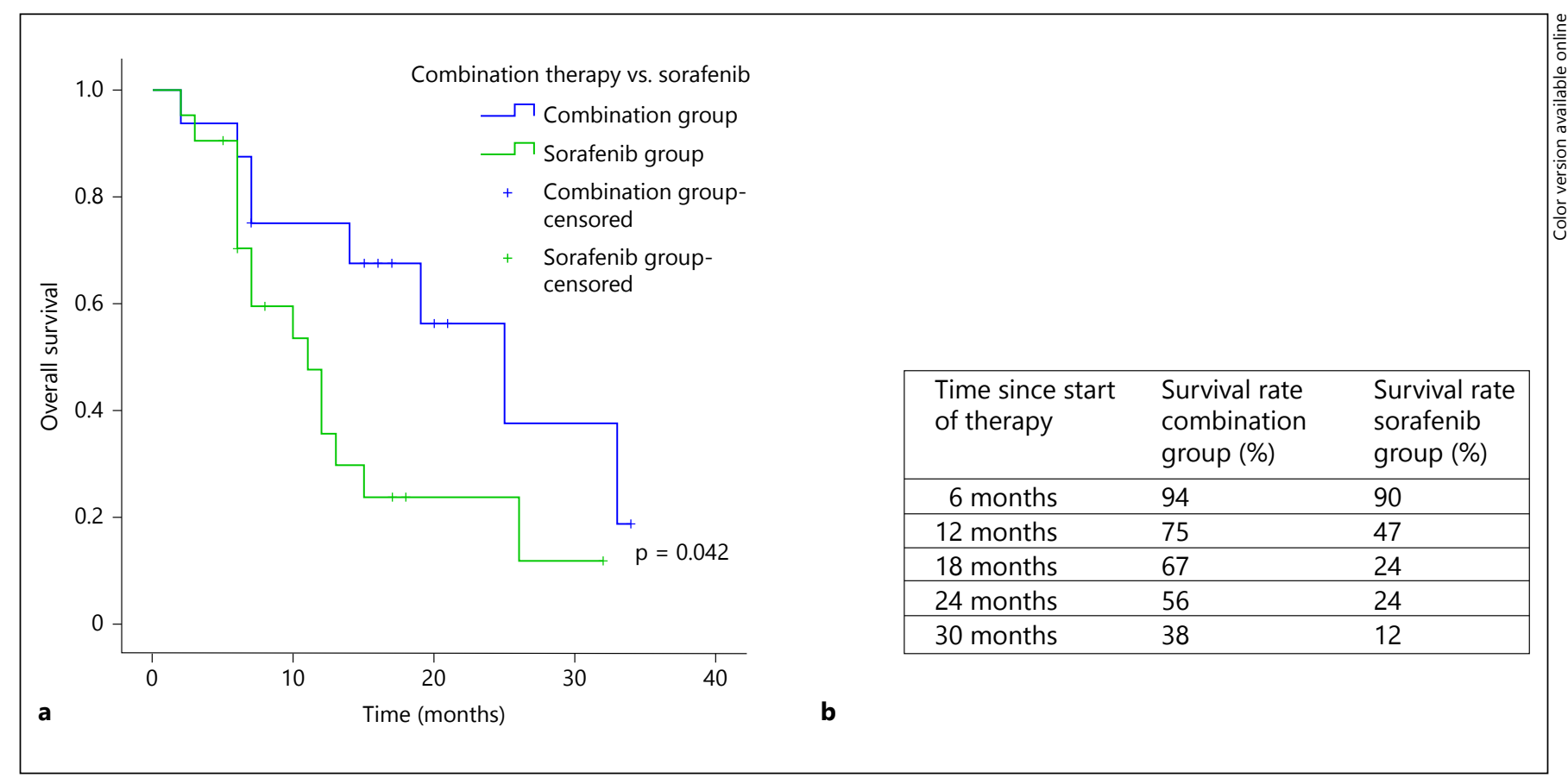

Fig. 1. Kaplan-Meier analysis of overall survival (left) and survival rate (right). For combination group $=$ TACE/SIRT plus sorafenib and sorafenib only group. The median overall survival was 25

\section{Overall Survival}

As shown in figure 1a, patients treated with local hepatic therapy (TACE/SIRT) in addition with sorafenib showed a significantly increased median overall survival time of 25 months (95\% confidence interval: 13.7-36.3 months) as compared to patients treated with sorafenib alone (11 months, 95\% CI: 6.2-15.8 months) ( $\mathrm{p}=0.042$ ). After 6 months of follow-up, survival rates were $94 \%$ (combination group) versus $90 \%$ (sorafenib group), and 75 versus $47 \%$ after 12 months of follow-up (fig. 1b). At the end of our evaluation 6 patients from the combination group and 2 patients from the sorafenib group were still under treatment.

To avoid a bias due to the presence of more patients with partial and complete portal lacking complete PVT and for a cohort lacking both complete and partial PVT, we observed for both cohorts a significant better OS in the combined treatment group (fig. 2).

\section{Time to Progression}

Patients treated with combined therapy seemed to progress more slowly median time to progression of 7 months (95\% CI: 5.3-8.7 months) versus 5 months (95\% CI: 3-7 months); however, this difference was not months (95\% confidence interval: $13.7-36.3$ months) in the combination group and 11 months (95\% CI: 6.2-15.8 months) in the sorafenib group $(\mathrm{p}=0.042)$.

significant $(\mathrm{p}=0.531)$ (fig. 3a). Median time to intrahepatic progression was 7 months (95\% KI: $0-15.23$ months) versus 8 months (95\% KI: $5.96-10.04$ months) in the combined versus sorafenib only group (fig. 3b). Median time to extrahepatic progression was 11 months $(95 \% \mathrm{CI}$ : 2.68-19.32 months) in the combined group versus 12 months (95\% CI: 0-26.53 months) in the sorafenib only group (fig. 3c). There were neither statistically significant differences in the median time to extrahepatic $(\mathrm{p}=0.701)$ nor in the time to intrahepatic progression $(\mathrm{p}=0.938)$ between the two treatment groups.

\section{Response Evaluation}

Patients treated with combined therapy seemed to show a higher rate of disease stabilisation and more partial responses (although not statistically significant). Disease progression seemed to be delayed at 3, 6, and 9 months compared to the sorafenib group (fig. $4 \mathrm{a}-\mathrm{c}$ ). After 12 months there was only a slight difference between the two groups (fig. 4d). Disease control rate (= complete remission plus partial response plus stable disease) after 3, 6, 9, and 12 months was always higher in the combined treatment group compared to the sorafenib group (fig. 5). 


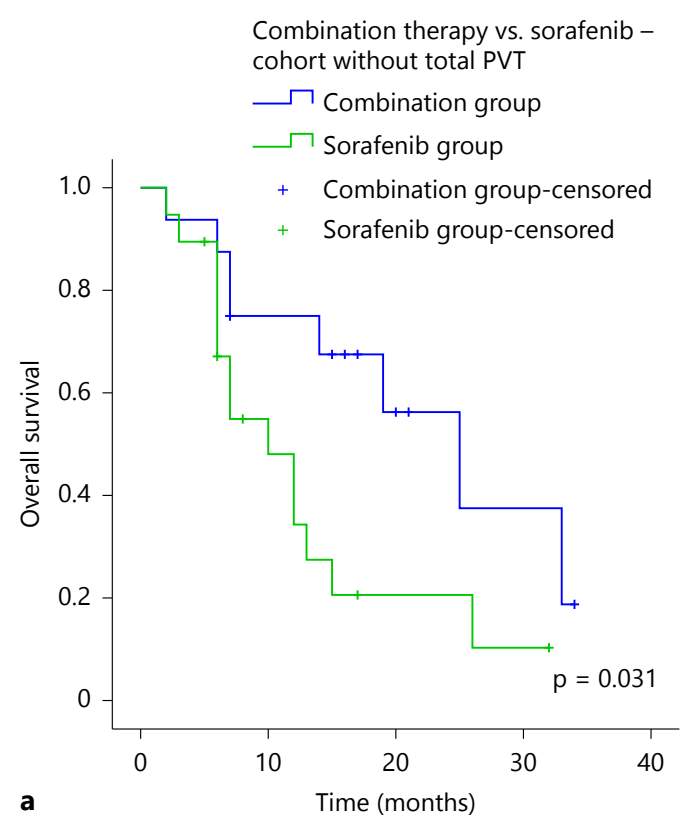

Fig. 2. Kaplan-Meier analysis of overall survival for cohorts without complete PVT and without partial or complete portal vein thrombosis (PVT). To avoid a bias due to the presence of complete PVT in the sorafenib group, data was calculated for a cohort with-

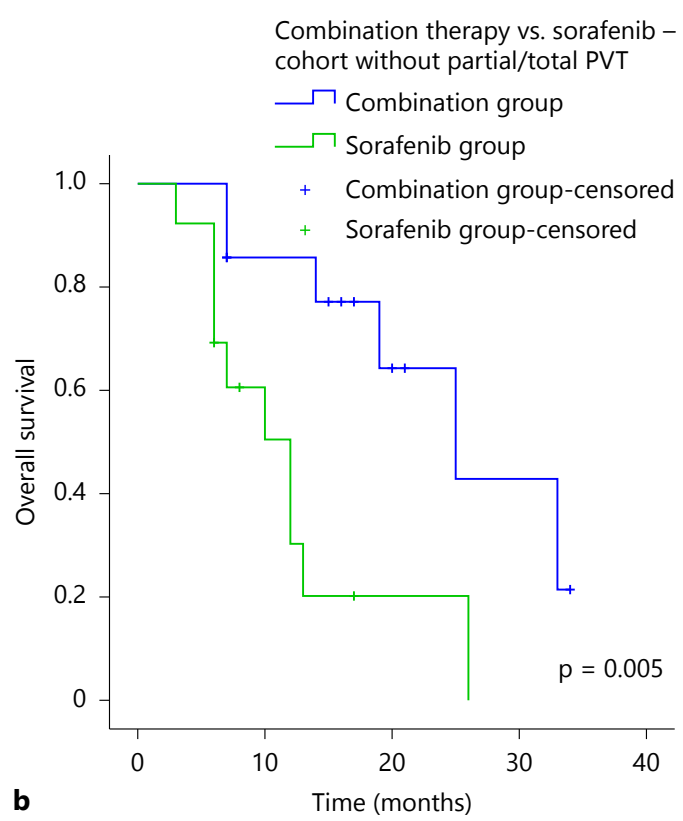

out complete (= total) PVT still showing a significant better OS in the combined group $(p=0.031)$. Data was also calculated for a cohort without any PVT also showing a significant better OS for the combined group $(\mathrm{p}=0.05)$.

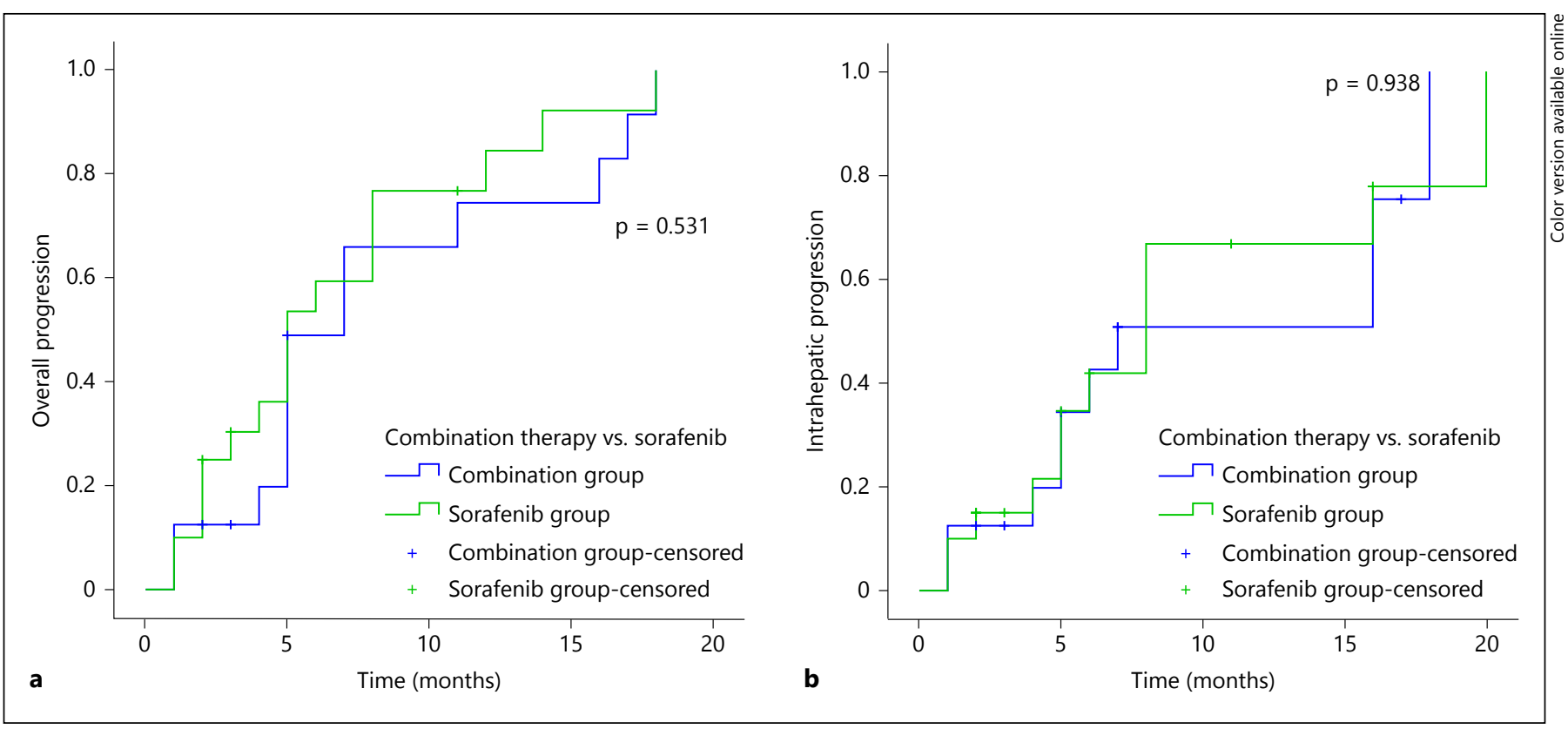

Fig. 3. Kaplan-Meier analysis for time to progression. a shows time to overall progression. The median time to overall progression was 7 months (95\% CI: 5.3-8.7 months) in the combined group and 5 months (95\% CI: 3-7 months) in the sorafenib group and this difference was not significant $(\mathrm{p}=0.531)$. Time to intrahepatic

progression is shown in $\mathbf{b}$. The median time to intrahepatic progression was 7 months (95\% KI: $0-15.23$ months) versus 8 months (95\% KI: 5.96-10.04 months) in the combined versus the sorafenibonly group $(\mathrm{p}=0.938)$. 
Fig. 3. Kaplan-Meier analysis for time to progression. Time to extrahepatic progression is shown in c. The median time to extrahepatic progression was 11 months (95\% CI: 2.68-19.32 months) in the combined group versus 12 months (95\% CI: 0-26.53 months) in the sorafenib-only group $(\mathrm{p}=0.701)$.

Fig. 4. Therapy response evaluation. Figure 4 shows the percentage of partial responses, stable diseases and progressive diseases after 3, 6, 9 and 12 months according to RECIST 1.0. There was no case of complete remission in both groups. This evaluation was only performed for patients with sufficient data at these time points. Few patients could not be considered due to dropoff, loss-to-follow-up.
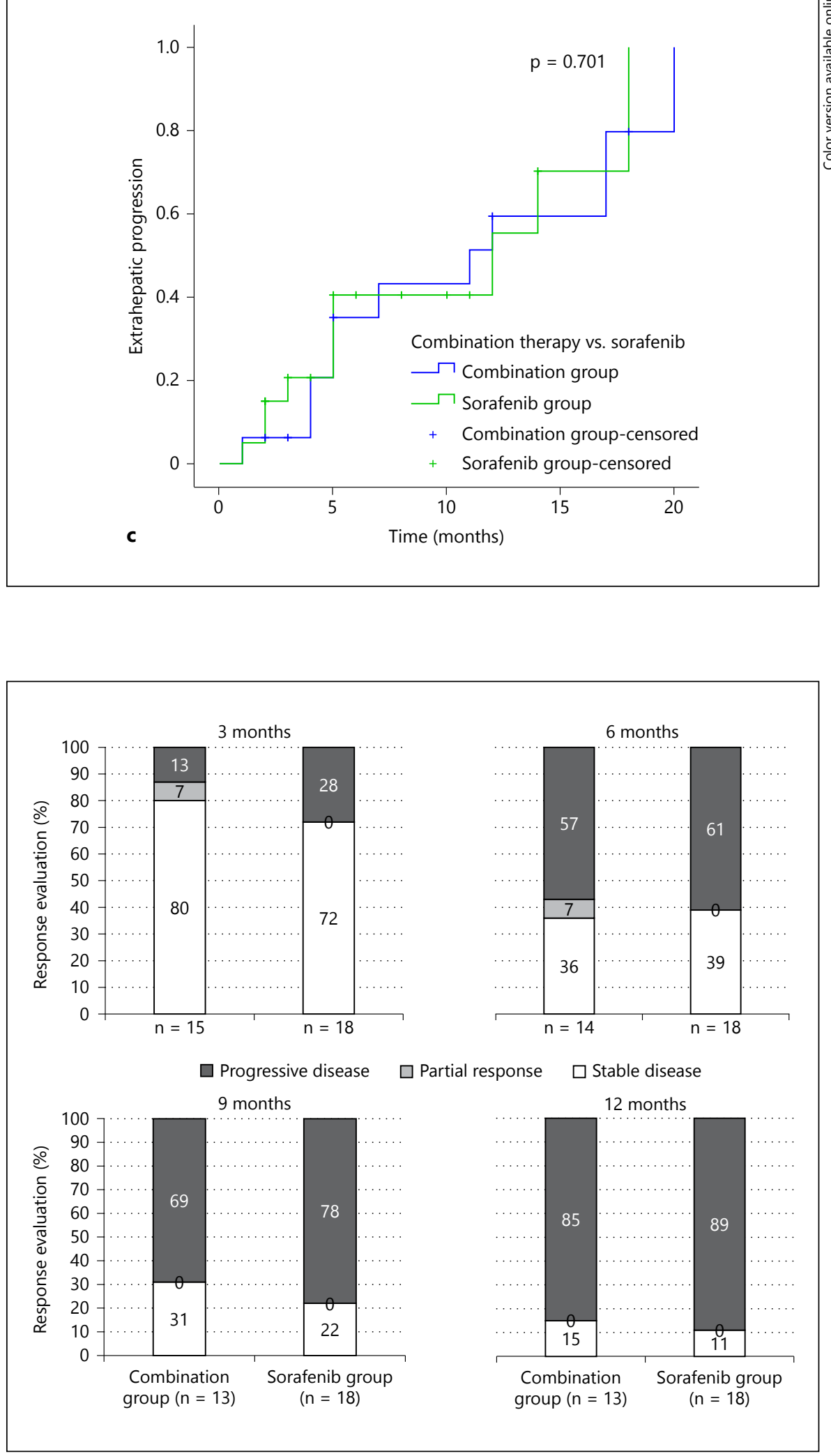

Schmidt/op den Winkel/Fischer/Straub/ Rauch/Paprottka/Göke/Kolligs 
Fig. 5. Disease control rate. Disease control rate (= complete remission plus partial response plus stable disease) after 3, 6, 9 and 12 months ( $\mathrm{p}>0.05)$.

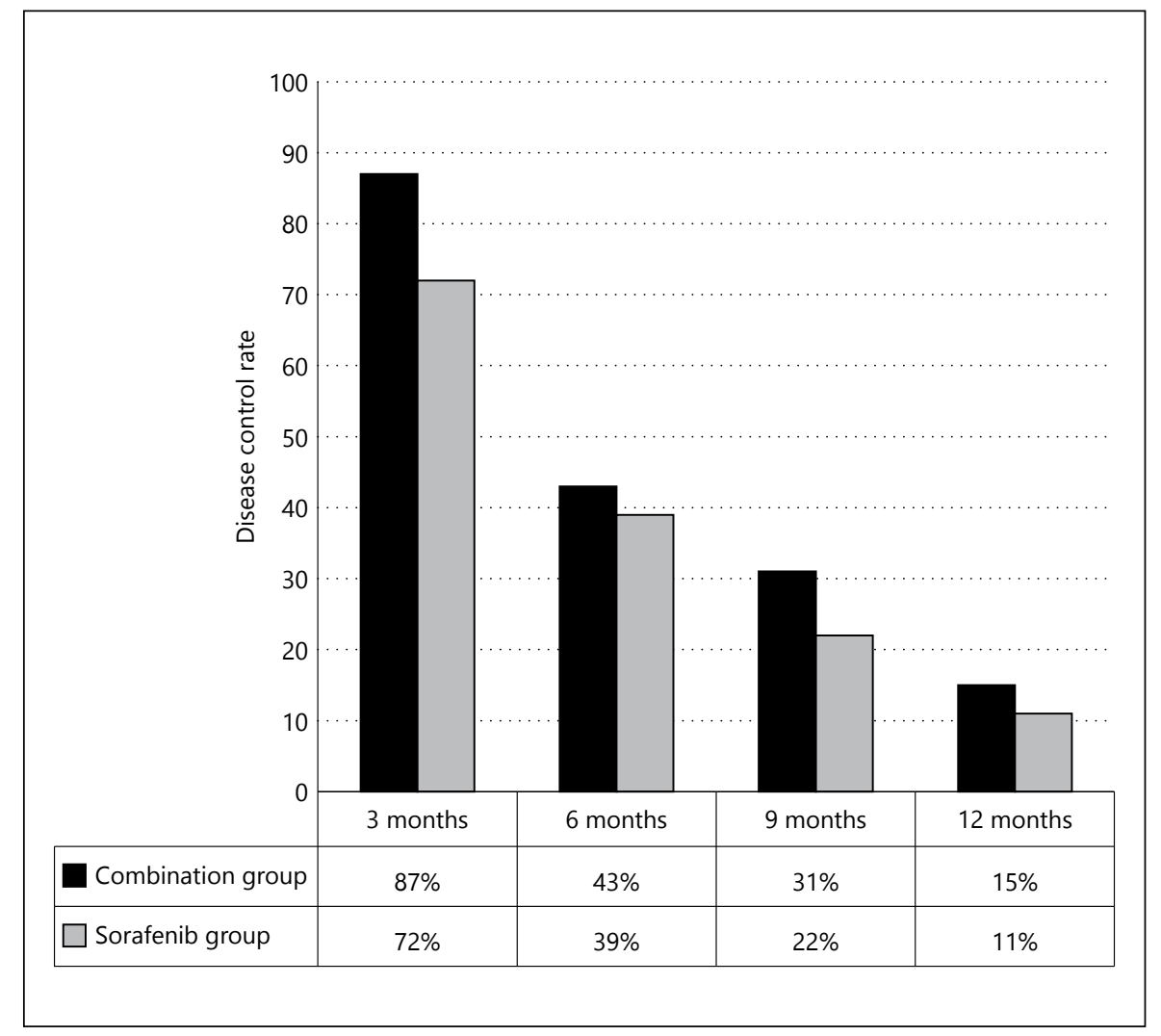

Hand-foot-skin reactions due to sorafenib occurred in $25.8 \%$ of the patients in the combined group and only in $4.8 \%$ in the sorafenib only group. Accordingly, dose reductions had to be done more often in the combined group ( $25 \%$ of the patients in the combined group vs. in $9.5 \%$ of the patients assigned to sorafenib only). The combined treatment was well tolerated by the small number of SIRT patients, 3 of 5 patients had SIRT twice, but dose reduction of sorafenib was also necessary in 3 of 5 patients of this group.

The Median Child Pugh score at the beginning of treatment was 5 points in each group; even during the course of treatment (Child Pugh score was assessed at each staging), there was no significant difference ( $\mathrm{p}=$ 0.328 ) between the two groups (online suppl. fig. 1; for all online suppl. material, see www.karger.com/doi/10.1159/ 000367686). Also, changes of INR over time were not statistically different $(p=0.841)$. Median bilirubin at the beginning of treatment was similar $(1.05 \mathrm{mg} / \mathrm{dl}$ in the combined and $1.1 \mathrm{mg} / \mathrm{dl}$ in the sorafenib group). However, bilirubin increased significantly to higher levels in the sorafenib group during treatment $(\mathrm{p}=0.049)$. In the combined group, the median AFP level decreased at the be- ginning of treatment but increased during the course of treatment; conversely, it increased continuously in the sorafenib group $(\mathrm{p}<0.001)$ (online suppl. fig. 2).

\section{Discussion}

For HCC patients in the advanced metastatic stage (BCLC C, Barcelona Clinic Liver Cancer Group), guidelines recommend systemic treatment with the multikinase inhibitor sorafenib [2, 3]. A major activity of sorafenib is the inhibition of neoangiogenesis, thereby arresting tumour growth by acting on growth factor receptors like VEGFR and PDGFR, Raf signalling and c-Kit $[10,11]$. Its efficacy has been demonstrated in two placebo-controlled, randomised phase III trials $[12,13]$. The multicenter, double-blind SHARP study, carried out on 602 patients, showed a median overall survival of 10.7 months after treatment with sorafenib compared to 7.9 months in the placebo group [12]. The Asia Pacific study assessed a median overall survival of 6.5 vs. 4.2 months [13]. Safety data were reproduced in the large phase IV GIDEON study [14]. 
Transarterial chemoembolisation has become the standard treatment for patients in the non-metastatic stage not suitable for curative therapy like resection, transplantation and image-guided tumour ablation [1, $15]$.

Several large studies have reported a survival benefit from TACE for patients in an intermediate stage of disease (BCLC B: multinodular tumour lesions, performance status 0, Child Pugh A-B) [16-19]. Less data is available for a survival benefit after treatment with selective internal radiotherapy (SIRT) [20-22].

A single-centre prospective study of 80 Child Pugh A patients in the BCLC stage B with HCV associated HCC showed a benefit of sorafenib therapy versus placebo following TACE treatment (TTP of 9.2 vs. 4.9 months) [23]. Similar results were observed in a Japanese and Korean phase III study, where 458 patients in the nonmetastatic stage with Child Pugh A received either sorafenib or placebo following TACE treatment. The median survival period after a sequential therapy of TACE and sorafenib was 29.7 months (however, the median survival after placebo treatment was not assessed). Regarding TTP, there was a slight difference of 5.4 versus 3.7 months between the sorafenib and the placebo group [24]. It was recently reported in two phase II trials that the combination of TACE and sorafenib at the same time is well tolerated by patients in the intermediate stage (BCLC B) and advanced metastastic stage (BCLC C) $[5,25,26]$. However, overall survival was not assessed. There are recent studies that showed that patients in the intermediate stage of disease treated with TACE might benefit from an additional simultaneous systemic therapy $[4,5,27,28]$. A reason for the benefit of combination therapy might be that sorafenib inverses the proangiogenic effect of TACE treatment. The safety of combined treatment was shown in a large randomised phase II trial (SPACE study) [29]. This study, which enrolled 307 HCC patients in the advanced non-metastatic stage who were randomised in a group treated simultaneously with TACE and sorafenib or in a group treated with TACE and placebo, showed a slight benefit of the combined therapy regarding TTP (median TTP in the 50th percentile 196 vs. 166 days, 112 vs. 88 in the 25 th percentile and 285 vs. 224 in the 75 th percentile in the sorafenib vs. placebo group, HR 0.797) but (not yet) a significant difference in OS [29].

Cause of death for patients in the metastatic stage is rather due to intrahepatic disease progression with consecutive liver failure than due to extrahepatic disease progression [7]. An additional local hepatic therapy for pa- tients treated with sorafenib might improve the outcome for patients in the metastatic stage. We assessed the benefit of combination therapy of sorafenib with local hepatic treatment for patients in the advanced metastatic stage (BCLC C) in a retrospective study of 37 patients. Regarding the baseline patient and tumour characteristics including age, gender, presence of cirrhosis, Child Pugh Score, presence of portal vein thrombosis, and liver tumour burden, there were no significant differences between the two treatment groups. We observed a significant higher overall survival of 25 months in the combination group compared to 11 months after sorafenib treatment alone. Survival time for patients under sorafenib treatment was similar to the SHARP study result [12]. The retrospective study by Qu et al., carried out on 45 patients of HCC in the intermediate and advanced stages, observed a similar overall survival of 27 months after combined TACE and sorafenib treatment compared to 17 months after TACE treatment alone [4].

Patients with complete portal vein thrombosis are usually not treated by TACE and are supposed to have a worse prognosis. In order to prove that the worse prognosis of the sorafenib only group is not due to the presence of more patients with partial and complete portal vein thrombosis in this group we calculated the data for a cohort lacking complete portal vein thrombosis and for a cohort lacking any type of portal vein thrombosis. We assessed a significant better OS in the combined group demonstrating that this is not due to the presence of complete PVT in the sorafenib group.

We observed a higher disease control rate in the combination group after 12 months of follow-up. In our study, the disease seemed to progress more slowly after combined treatment compared to sorafenib treatment alone 7 months (95\% CI: 5.3-8.7) versus 5 months (95\% CI: 3-7). However, this difference regarding the TTP was not statistically significant between the two therapy arms. Accordingly, there was a significant difference neither in the intrahepatic nor in the extrahepatic progress. TTP measures the time until the first progression and the effect of combined treatment might be seen later during time course. Accordingly, although there was no significant difference in the time course of liver function, AFP levels increased significantly faster in the sorafenib-only group. This might indicate a faster progress in the sorafenib group over the course of treatment independently of the liver function. This is supported by the higher disease control rate in the combined group.

The main limiting factors of our study are the small number of patients and the retrospective setting. This 
may have caused the missing of some data and a bias in some cases. The main baseline characteristics at the beginning of treatment however were not statistically significant between the two groups. During the time course of treatment, some laboratory results could not be assessed for all patients. The decision for a combined or sorafenib only treatment was made individually based on clinical criteria. About $56.2 \%$ of patients in the combination group versus $38.1 \%$ in the sorafenib group showed a metastatic stage when first diagnosed for HCC. Patients who were first diagnosed at the metastatic stage might have been offered a combined treatment rather than sorafenib treatment alone. Patients who showed disease progression after prior therapies might have rather received sorafenib alone rather than the combination. However, the number of patients with prior therapies was not significantly different in both groups ( 8 vs. 12 patients in the combined vs. the sorafenib group). Although more dose reductions had to be done in the combination group (due to hand-foot-skin reaction) than in the sorafenib group ( $25 \mathrm{vs.} 9.5 \%$ ), patients showed a higher rate of therapy response in the combined group.

\section{Conclusion}

Recent studies showed that HCC patients in the intermediate stage of disease treated with TACE might benefit of an additional systemic therapy. A reason for that might be that sorafenib inverses the proangiogenic effect of TACE treatment. Cause of death for patients in the metastatic stage is intrahepatic rather than extrahepatic progression of disease. Our study suggests that patients in the metastastic stage of disease might benefit from local treatment of the primary liver lesions in addition to systemic therapy because we observed a significantly higher OS after combined treatment. However, studies with higher numbers of patients in a prospective trial are needed before general recommendations for a combination therapy could be given to patients in the metastatic stage.

\section{Acknowledgements}

There is no external funding for this study. Conceived and designed study: LS, MODW, KF, FTK, BG. Performed study: LS, KF, FTK. Contributed materials/analysis tools: MODW, GS, BR, PMP This work is part of the thesis of KF.

\section{References}

1 Forner A, Llovet JM, Bruix J: Hepatocellular carcinoma. Lancet 2012;379:1245-1255.

$\checkmark 2$ Bruix J, Sherman M: Management of hepatocellular carcinoma: an update. Hepatology 2011;53:1020-1022.

-3 EASL-EORTC clinical practice guidelines: management of hepatocellular carcinoma. J Hepatol 2012;56:908-943.

$\checkmark 4 \mathrm{Qu}$ XD, Chen CS, Wang JH, Yan ZP, Chen JM, Gong GQ, Liu QX, Luo JJ, Liu LX, Liu R, Qian S: The efficacy of TACE combined sorafenib in advanced stages hepatocellullar carcinoma. BMC Cancer 2012;12:263.

5 Chung YH, Han G, Yoon JH, Yang J, Wang J, Shao GL, Kim BI, Lee TY, Chao Y: Interim analysis of START: study in Asia of the combination of TACE (transcatheter arterial chemoembolisation) with sorafenib in patients with hepatocellular carcinoma trial. Int J Cancer 2013;132:2448-2458.

-6 Duan F, Wang MQ, Liu FY, Wang ZJ, Song P, Wang Y: Sorafenib in combination with transarterial chemoembolisation and bronchial arterial chemoinfusion in the treatment of hepatocellular carcinoma with pulmonary metastasis. Asia Pac J Clin Oncol 2012;8:156163.

7 Uka K, Aikata H, Takaki S, Shirakawa H, Jeong SC, Yamashina K, Hiramatsu A, Kodama H, Takahashi S, Chayama K: Clinical features and prognosis of patients with extrahepatic metas- tases from hepatocellular carcinoma. World J Gastroenterol 2007;13:414-420.

8 Therasse P, Arbuck SG, Eisenhauer EA, Wanders J, Kaplan RS, Rubinstein L, Verweij J, Van Glabbeke M, van Oosterom AT, Christian MC, Gwyther SG: New guidelines to evaluate the response to treatment in solid tumors. European Organization for Research and Treatment of Cancer, National Cancer Institute of the United States, National Cancer Institute of Canada. J Natl Cancer Inst 2000;92:205-216.

-9 Eisenhauer EA, Therasse P, Bogaerts J, Schwartz LH, Sargent D, Ford R, Dancey J, Arbuck S, Gwyther S, Mooney M, Rubinstein L, Shankar L, Dodd L, Kaplan R, Lacombe D, Verweij J: New response evaluation criteria in solid tumours: revised RECIST guideline (version 1.1). Eur J Cancer 2009;45:228-247.

10 Chang YS, Adnane J, Trail PA, Levy J, Henderson A, Xue D, Bortolon E, Ichetovkin $\mathrm{M}$, Chen C, McNabola A, Wilkie D, Carter CA, Taylor IC, Lynch M, Wilhelm S: Sorafenib (BAY 43-9006) inhibits tumor growth and vascularization and induces tumor apoptosis and hypoxia in RCC xenograft models. Cancer Chemother Pharmacol 2007;59:561-574.

-11 Wilhelm SM, Adnane L, Newell P, Villanueva A, Llovet JM, Lynch M: Preclinical overview of sorafenib, a multikinase inhibitor that targets both Raf and VEGF and PDGF receptor tyrosine kinase signaling. Mol Cancer Ther 2008;7:3129-3140.

12 Llovet JM, Ricci S, Mazzaferro V, Hilgard P, Gane E, Blanc JF, de Oliveira AC, Santoro A, Raoul JL, Forner A, Schwartz M, Porta C, Zeuzem S, Bolondi L, Greten TF, Galle PR, Seitz JF, Borbath I, Haussinger D, Giannaris T, Shan M, Moscovici M, Voliotis D, Bruix J: Sorafenib in advanced hepatocellular carcinoma. N Engl J Med 2008;359:378-390.

13 Cheng AL, Kang YK, Chen Z, Tsao CJ, Qin S, Kim JS, Luo R, Feng J, Ye S, Yang TS, Xu J, Sun Y, Liang H, Liu J, Wang J, Tak WY, Pan H, Burock K, Zou J, Voliotis D, Guan Z: Efficacy and safety of sorafenib in patients in the Asia-Pacific region with advanced hepatocellular carcinoma: a phase III randomised, double-blind, placebocontrolled trial. Lancet Oncol 2009;10:25-34.

-14 Lencioni R, Kudo M, Ye SL, Bronowicki JP, Chen XP, Dagher L, Furuse J, Geschwind JF, Ladron de Guevara L, Papandreou C, Sanyal AJ, Takayama T, Yoon SK, Nakajima K, Cihon F, Heldner S, Marrero JA: First interim analysis of the GIDEON (Global Investigation of therapeutic decisions in hepatocellular carcinoma and of its treatment with sorafe $\mathrm{Nib)} \mathrm{non-interventional} \mathrm{study.} \mathrm{Int} \mathrm{J} \mathrm{Clin}$ Pract 2012;66:675-683.

15 Bruix J, Sala M, Llovet JM: Chemoembolization for hepatocellular carcinoma. Gastroenterology 2004;127:S179-S188.
Addition of Local Hepatic Therapy to Sorafenib in Advanced HCC
Digestion 2014;90:219-228 DOI: $10.1159 / 000367686$ 
16 Llovet JM, Bruix J: Systematic review of randomized trials for unresectable hepatocellular carcinoma: chemoembolization improves survival. Hepatology 2003;37:429-442.

17 Llovet JM, Real MI, Montana X, Planas R, Coll S, Aponte J, Ayuso C, Sala M, Muchart J, Sola R, Rodes J, Bruix J: Arterial embolisation or chemoembolisation versus symptomatic treatment in patients with unresectable hepatocellular carcinoma: a randomised controlled trial. Lancet 2002;359:1734-1739.

18 Camma C, Schepis F, Orlando A, Albanese M, Shahied L, Trevisani F, Andreone P, Craxi A, Cottone M: Transarterial chemoembolization for unresectable hepatocellular carcinoma: meta-analysis of randomized controlled trials. Radiology 2002;224:47-54.

$\checkmark 19$ Lo CM, Ngan H, Tso WK, Liu CL, Lam CM, Poon RT, Fan ST, Wong J: Randomized controlled trial of transarterial lipiodol chemoembolization for unresectable hepatocellular carcinoma. Hepatology 2002;35:1164-1171.

20 Kulik LM, Atassi B, van Holsbeeck L, Souman T, Lewandowski RJ, Mulcahy MF, Hunter RD, Nemcek AA Jr, Abecassis MM, Haines KG 3rd, Salem R: Yttrium-90 microspheres (TheraSphere) treatment of unresectable hepatocellular carcinoma: downstaging to resection, RFA and bridge to transplantation. J Surg Oncol 2006;94:572-586.
21 Geschwind JF, Salem R, Carr BI, Soulen MC, Thurston KG, Goin KA, Van Buskirk M, Roberts CA, Goin JE: Yttrium-90 microspheres for the treatment of hepatocellular carcinoma. Gastroenterology 2004;127:S194-S205.

22 Sangro B, Carpanese L, Cianni R, Golfieri R, Gasparini D, Ezziddin S, Paprottka PM, Fiore F, Van Buskirk M, Bilbao JI, Ettorre GM, Salvatori R, Giampalma E, Geatti O, Wilhelm K, Hoffmann RT, Izzo F, Inarrairaegui M, Maini CL, Urigo C, Cappelli A, Vit A, Ahmadzadehfar H, Jakobs TF, Lastoria S: Survival after yttrium-90 resin microsphere radioembolization of hepatocellular carcinoma across Barcelona clinic liver cancer stages: a European evaluation. Hepatology 2011;54:868-878.

23 Sansonno D, Lauletta G, Russi S, Conteduca V, Sansonno L, Dammacco F: Transarterial chemoembolization plus sorafenib: a sequential therapeutic scheme for HCV-related intermediate-stage hepatocellular carcinoma: a randomized clinical trial. Oncologist 2012;17: 359-366.

24 Kudo M, Imanaka K, Chida N, Nakachi K, Tak WY, Takayama T, Yoon JH, Hori T, Kumada H, Hayashi N, Kaneko S, Tsubouchi H, Suh DJ, Furuse J, Okusaka T, Tanaka K, Matsui $O$, Wada M, Yamaguchi I, Ohya T, Meinhardt G, Okita K: Phase III study of sorafenib after transarterial chemoembolisation in Japanese and Korean patients with unresectable hepatocellular carcinoma. Eur J Cancer 2011;47:2117-2127.
25 Pawlik TM, Reyes DK, Cosgrove D, Kamel IR, Bhagat N, Geschwind JF: Phase II trial of sorafenib combined with concurrent transarterial chemoembolization with drug-eluting beads for hepatocellular carcinoma. J Clin Oncol 2011;29:3960-3967.

26 Zhao Y, Wang WJ, Guan S, Li HL, Xu RC, Wu JB, Liu JS, Li HP, Bai W, Yin ZX, Fan DM, Zhang ZL, Han GH: Sorafenib combined with transarterial chemoembolization for the treatment of advanced hepatocellular carcinoma: a large-scale multicenter study of 222 patients. Ann Oncol 2013;24:17861792.

27 Park MS, Kim SU, Park JY, Kim do Y, Ahn $\mathrm{SH}$, Han KH, Chon CY, Seong J: Combination treatment of localized concurrent chemoradiation therapy and transarterial chemoembolization in locally advanced hepatocellular carcinoma with intrahepatic metastasis. Cancer Chemother Pharmacol 2013; 71:165-173.

28 Dufour JF: TACE with or without systemic therapy? J Hepatol 2012;56:1224-1225.

29 Lencioni R, Zou J, Leberre M, Meinhardt G, Voliotis D, Bruix J, Llovet M: Sorafenib (SOR) or placebo (PL) in combination with transarterial chemoembolization (TACE) for intermediate-stage hepatocellular carcinoma (SPACE). J Clin Oncol 2010;28:TPS178. 